\title{
Cardiopatia chagásica crônica no Rio Negro, Estado do Amazonas. Relato de três novos casos autóctones, comprovados por exames sorológicos, clínicos, radiográficos do tórax, eletro e ecocardiográficos
}

\author{
Chronic chagasic cardiopathy in the Rio Negro, Amazon State. Report of three new \\ autochthonous cases confirmed by serology, clinical examination, \\ chest X-rays, electro and echocardiography
}

\author{
Sérgio Salles Xavier ${ }^{1}$, Andréa Silvestre Sousa ${ }^{1}$, Pedro Albajar Viñas ${ }^{2}$, Angela C.V. Junqueira ${ }^{2}$, \\ Márcio Neves Bóia ${ }^{2,3}$ e José Rodrigues Coura ${ }^{2}$
}

\begin{abstract}
RESUMO
São relatados três novos casos de miocardiopatia chagásica crônica em pacientes autóctones do Rio Negro, Estado do Amazonas, confirmados por sorologia (imunofluorescência, ELISA e Western-blot para infecção pelo Trypanosoma cruzi) e por exames clínicos, radiográficos, eletro e ecocardiográficos. Os pacientes nasceram e sempre viveram na região do Rio Negro, tendo sido picados numerosas vezes por triatomíneos silvestres em piaçabais da área. O quadro clínico foi de insuficiência cardíaca congestiva e distúrbio da condução intraventricular nos três casos (BRD com HBAE em dois casos e BRE de terceiro grau em um caso), extra-sístoles ventriculares polimórficas em dois casos e alteração primária da repolarização ventricular em um deles. A avaliação ecocardiográfica revelou importante aumento dos diâmetros cavitários do VE, com fração da ejeção < 36\% e padrão segmentar de acometimento miocárdico, incluindo aneurisma apical e acinesia ínfero-posterior nos três pacientes. Estes são os primeiros casos descritos de cardiopatia chagásica crônica autóctone do Amazonas com padrão ecocardiográfico sugestivo da doença.
\end{abstract}

Palavras-chaves: Cardiopatia chagásica crônica. Casos autóctones. Rio Negro. Amazônia brasileira.

\begin{abstract}
We report three new autochthonous cases of chronic chagasic cardiomyopathy from Rio Negro, Amazon State, confirmed by serology (indirect immunofluorescence, ELISA and Western-blot for Trypanosoma cruzi infection), clinical examination, chest $X$-rays, electro- and echocardiography. The three patients were born and lived all their lives in the Rio Negro region working as piaçaba gatherers, where they were bitten several times by sylvatic triatomine bugs. The clinical feature was congestive heart failure and intraventricular conduction impairment in the three cases (right bundle branch block with left anterior hemiblock in two cases, left bundle branch block of $3^{\text {rd }}$ degree in one), polimorphic ventricular extrasystoles in two cases and primary $T$ wave inversion in another one. The echocardiographic evaluation showed a significant increasing of the left ventricular diameters with ejection fraction lesser than $36 \%$, and myocardial segmental impairment pattern, including apical aneruysm and posteroinferior akinesia in the three patients. These are the first autochthonous cases of chronic Chagasic cardiomyopathy from the Brazilian Amazon state with echocardiographic pattern suggestive of Chagas' disease.
\end{abstract}

Key-words: Chronic Chagasic cardiopathy. Autochthonous cases. Rio Negro. Brazilian Amazon.

\footnotetext{
1. Instituto de Pesquisa Clínica Evandro Chagas da Fundação Oswaldo Cruz, Rio de Janeiro, RJ. 2. Departamento de Medicina Tropical do Instituto 0swaldo Cruz da Fundação Oswaldo Cruz, Rio de Janeiro, RJ. 3. Disciplina de Doenças Infecciosas e Parasitárias da Universidade do Estado do Rio de Janeiro, Rio de Janeiro, RJ. Endereço para correspondência: Prof. José Rodrigues Coura. Deptº de Medicina Tropical/FIOCRUZ. Av. Brasil 4365, 21045-900 Rio de Janeiro, RJ. e-mail: coura@ioc.fiocruz.br

Recebido para publicação em 5/10/2005

Aceito em 3/2/2005
} 
A infecção chagásica humana na Amazônia brasileira tem sido descrita desde 1969, quando foram relatados os primeiros casos agudos ${ }^{22}$. Desde então, diversos casos de doença de Chagas aguda foram descritos naquela região, principalmente nos últimos dez anos, a maioria como microepidemias supostamente relacionadas ao consumo de aça1 ${ }^{192627}$. Inquérito sorológico nacional realizado entre 1975 e 1980, pela SUCAM (atual Fundação Nacional de Saúde), demonstrou uma prevalência de infecção chagásica de 2,4\% no Acre e 1,8\% no Amazonas, com concentração de 6,5\% no Município de Barcelos ${ }^{1023}$. Estes dados foram ampliados a partir de 1991, pelo nosso grupo, com a realização de vários inquéritos sorológicos e estudos seccionais, incluindo avaliação clínica e eletrocardiográfica de pacientes sorologicamente positivos nas áreas urbana e rural de Barcelos e em diversas populações ribeirinhas e piaçabais do rio Negro e seus afluentes. Estes estudos comprovaram a elevada prevalência de infecção chagásica nesta região e demonstraram um perfil de baixa morbidade na fase crônica da doença, atribuída à baixa parasitemia e/ou a menor patogenicidade do Trypanosoma cruzi silvestre presente na região, com homologia genética, mas com grande heterogeneidade fenética e patogênica experimentalmente $e^{131415}$.

Mais recentemente, desenvolvemos um estudo de busca ativa de casos autóctones de cardiopatia crônica naquela região, quando encontramos dois casos de miocardiopatia dilatada grave com sorologia positiva para infecção chagásica os quais evoluíram para o óbito². Apesar da presença da reação em cadeia da polimerase (PCR) para T. cruzi, em material de fragmento cardíaco post mortem do coração de um dos pacientes, os aspectos clínicos, eletrocardiográficos e ecocardiográficos destes dois casos foram diferentes dos habitualmente descritos na cardiopatia chagásica crônica clássica. Nos dois casos fatais, que descrevemos havia uma predominância de comprometimento do ventrículo esquerdo, inclusive com bloqueio de ramo esquerdo (BRE) de $3^{\circ}$ grau em um dos casos, achado pouco freqüente na cardiopatia chagásica ${ }^{18}$.

Em outubro de 2004, realizamos um novo estudo na região, com avaliação clínica, eletrocardiográfica e ecocardiográfica de uma série de 110 pacientes com história epidemiológica de longa exposição a triatomíneos em piaçabais ao longo do Rio Negro e seus afluentes e/ou pacientes com sintomatologia sugestiva de doença cardiovascular. Encontramos três novos casos de insuficiência cardíaca, com características clínicas, eletrocardiográficas e ecocardiográficas sugestivas de cardiopatia chagásica crônica, cuja sorologia foi positiva para T. cruzi, os quais serão descritos a seguir.

Os pacientes foram submetidos à avaliação sorológica e parasitológica para doença de Chagas, exame clínico, radiografia de tórax póstero-anterior, eletrocardiograma com as 12 derivações clássicas, ecocardiograma uni e bidimensional com Doppler e exame radiográfico contrastado de esôfago.

0 diagnóstico sorológico foi feito utilizando-se as técnicas de imunofluorescência indireta anti T. cruzi (IFI-Chagas BioManguinhos), testes ELISA convencional (EIE-Chagas BioManguinhos), teste ELISA recombinante com antígeno CraFra (EIE recombinante Chagas Bio-Manguinhos) e a técnica de Western blot TESA (Trypomastigote Excreted-Secreted antigen $)^{492528}$. Foram realizados ainda hemocultura em meio LIT/NNN, xenodiagnóstico direto e PCR 811221.

Foi utilizado um ecocardiógrafo portátil da marca ESAOTE, modelo SIM 5000, sendo realizados os cortes ecocardiográficos padrões (paraesternais, apicais e subcostais) e variações dos cortes convencionais apicais, importante para identificação de pequenos aneurismas apicais. As medidas de função de ventrículo esquerdo (VE) foram obtidas conforme preconizado pela Sociedade Americana de Ecocardiografia e a fração de ejeção foi estimada ao modo M pela técnica de Teicholz ${ }^{24}$. Devido ao padrão freqüentemente segmentar do acometimento miocárdico na cardiopatia chagásica crônica ${ }^{1729}$, a avaliação da função sistólica de VE também foi realizada ao bidimensional, de forma subjetiva, conforme preconizado por Amico cols ${ }^{56}$. A função contrátil do ventrículo direito (VD) foi avaliada através da excursão sistólica do anel tricúspide.

\section{RELATO DOS CASOS}

$1^{\circ}$ caso: 0AS, 53 anos de idade, masculino, natural da cidade de Barcelos, de onde logo depois de nascer foi levado ao igarapé Quimicuri, Rio Negro, onde morou até os dez anos de idade. Posteriormente, e durante 37 anos, morou e trabalhou na extração da piaçaba no rio Padauiri e seus afluentes. Há seis anos voltou a Cidade de Barcelos, deixando a atividade extrativista. 0 paciente referiu ter sido fumante e etilista ocasional até dois anos atrás.

o paciente nunca viajou para fora do Estado do Amazonas, nega ter recebido transfusão sanguínea e relatou ter sido picado muitas vezes por triatomíneos em piaçabais dos igarapés do rio Padauiri, referindo, também, ter apresentado vários caroços após as picadas no tronco e extremidades. Identificou o vetor em teste de reconhecimento, numa coleção de Panstrongylus, Rhodnius e Triatoma.

0 paciente foi diagnosticado de insuficiência cardíaca congestiva descompensada na Cidade de Manaus em 2004, para onde foi encaminhado por quadro clínico de cansaço aos pequenos esforços, com posterior edema de membros inferiores e dor em hipocôndrio direito de oito meses de evolução. Atualmente, diz estar assintomático com uso de captopril 50mg, furosemida 40mg e digoxina diários.

No exame físico, o paciente apresentou-se afebril, com pulso regular de 72 bpm e PA de 100/70mmHg. 0 ictus cordis era globoso e desviado para baixo um espaço intercostal. Na ausculta cardíaca destaca-se sopro sistólico $2 / 6+$, sugestivo de regurgitação mitral, irradiando para axila.

$\mathrm{Na}$ radiografia de tórax póstero-anterior, evidencia-se moderado aumento da área cardíaca com índice cardiotorácico de 0,62 (Figura 1).

No ECG, destaca-se um bloqueio de ramo direito (BRD) de $2^{\circ}$ grau com hemibloqueio anterior esquerdo (HBAE), extrasístoles ventriculares (EV) polimórficas, bigeminadas e alteração primária da repolarização ventricular (APRV) ántero-lateral. 


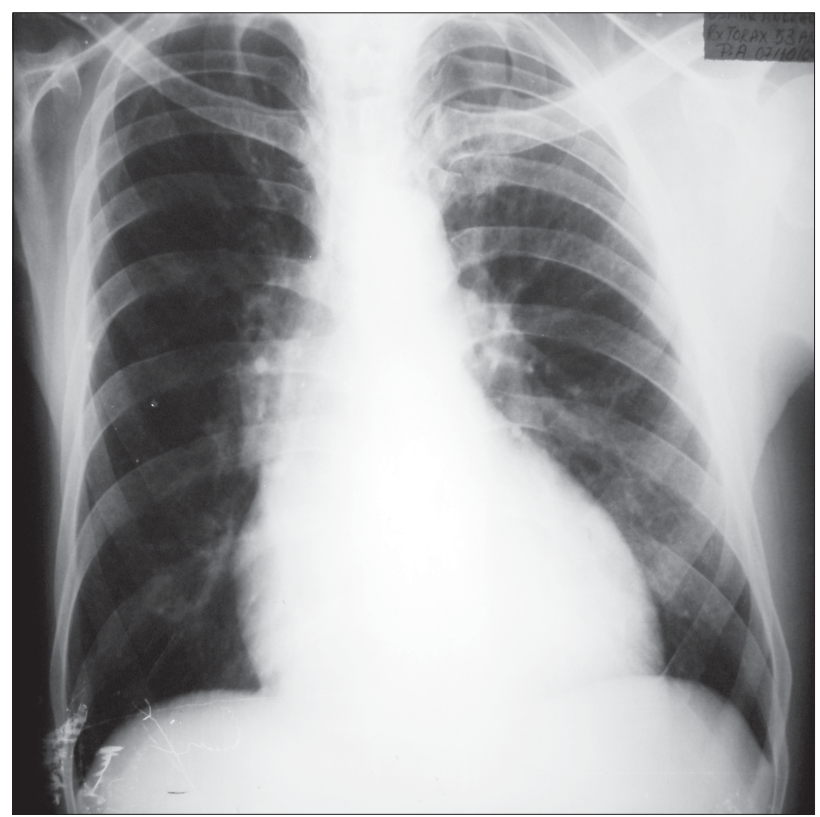

Figura 1 - Radiografia de tórax póstero-anterior com moderado aumento da área cardíaca (índice cardiotorácico de 0,62).

A avaliação ecocardiográfica revela importante aumento dos diâmetros cavitários do VE, com presença de aneurisma de ponta, afinamento e acinesia da parede ínfero-posterior e hipocinesia dos demais segmentos do VE, com grave disfunção sistólica global $(\mathrm{FE}=35 \%)$ (Figura 2). Nota-se ainda aumento de cavidades direitas, com disfunção contrátil do VD. A análise ao Doppler demonstra insuficiência mitral de grau moderado e disfunção diastólica de VE de grau II (padrão pseudonormal).

0 exame radiográfico contrastado de esôfago não evidenciou alterações funcionais ou morfológicas ${ }^{20}$.

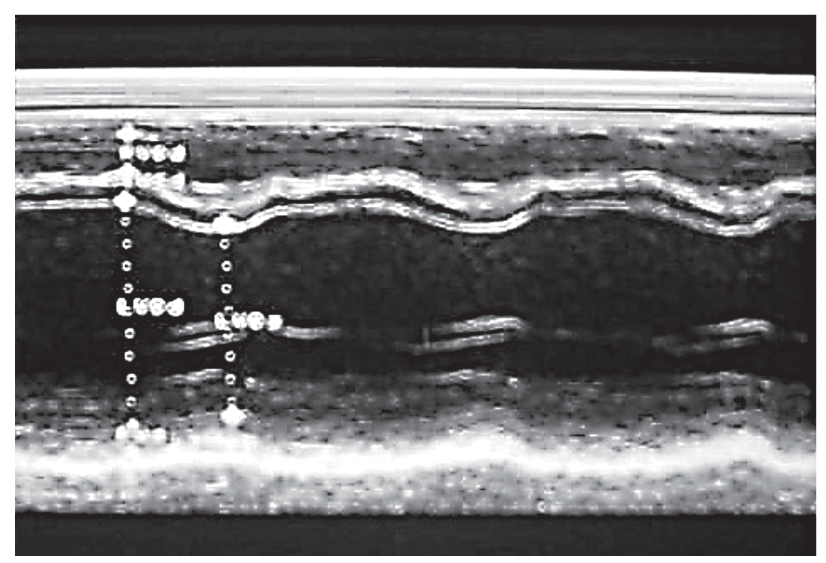

Figura 2 - Área de função de VE ao modo M. Nota-se importante aumento dos diâmetros cavitários do $\mathrm{VE}$, com afinamento da parede ínferoposterior, justificando os achados de acinesia e hipocinesia segmentar do VE e grave disfunção sistólica global $(F E=35 \%)$.

$2^{\circ}$ caso: MRR, 69 anos de idade, masculino, natural da cidade de Barcelos, de onde foi levado, com um ano de idade, para uma comunidade do rio Madeira, também no Estado do Amazonas, onde morou durante dez anos. Posteriormente, retornou ao Município de Barcelos iniciando a sua atividade extrativista da piaçaba nos rios Aracá e Curuduri, a qual exerceu de forma continuada até os 28 anos de idade, quando doença aguda em articulação do quadril esquerdo afastou-o definitivamente dessa atividade laboral. Há 41 anos que mora na Cidade de Barcelos, nunca viajou para fora do Estado do Amazonas e nega ter recebido transfusão sanguínea. Desde há cinco meses, refere ter parado hábito etílico ocasional, que iniciou aos 25 anos de idade.

0 paciente refere ter sido picado muitas vezes por triatomíneos em piaçabais dos igarapés dos rios Aracá e Curuduri, referindo, também, ter apresentado vários caroços após as picadas no tronco e extremidades; identificou o vetor em teste de reconhecimento com coleção de triatomíneos.

0 paciente refere quadro subagudo de quatro meses de evolução com cansaço e dispnéia progressiva aos pequenos esforços, ortopnéia e edema de membros inferiores. Há três meses, apresentou agravamento de seu quadro clínico com aumento da dispnéia, cansaço, edema progressivo e taquiarritmia, entre 120 e 160 batimentos por minuto, motivo pelo qual foi encaminhado a Cidade de Manaus. Atendido em serviço de emergência, foi visualizada uma cardiomegalia na radiografia torácica e foi revertido o ritmo cardíaco com medicação cardiológica.

Atualmente, o paciente apresenta pulso regular a $100 \mathrm{bpm}$ e PA de 120/70mmHg. No exame físico destaca-se um ictus cordis globoso, desviado para a esquerda e abaixo um espaço intercostal e na ausculta cardíaca apresenta um sopro sistólico de 3/6+ em ponta, irradiado para axila.

Na radiografia de tórax póstero-anterior evidencia-se moderado aumento de área cardíaca com índice cardiotorácico de 0,56.

No registro eletrocardiográfico nota-se BRD de $3^{\circ}$ grau com HBAE e EV polimórficas (Figura 3).

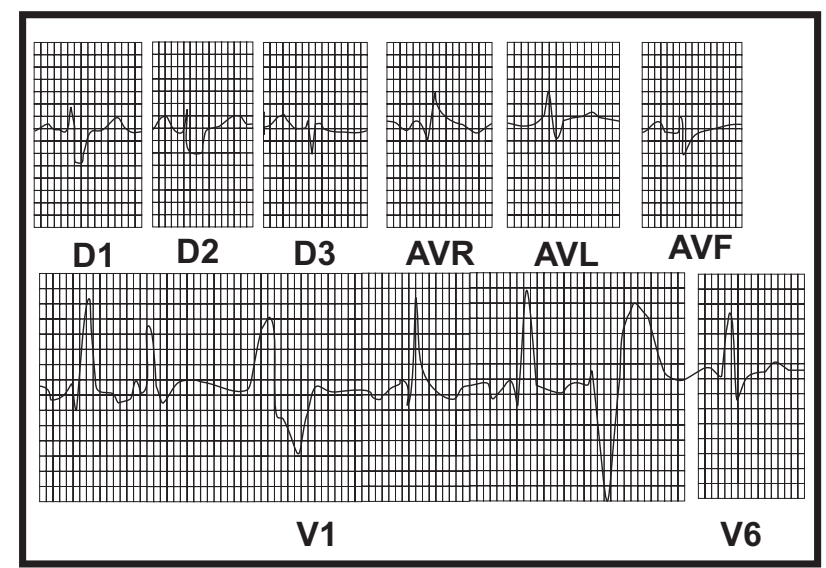

Figura 3 - Eletrocardiograma com BRD de $3^{\circ}$ grau, HBAE e EV polimórficas.

O ecocardiograma demonstra aumento dos diâmetros cavitários do VE com aneurisma apical, afinamento e acinesia ínfero-posterior e hipocinesia dos demais segmentos do VE, com grave disfunção sistólica global $(\mathrm{FE}=24 \%)$. Átrios $\mathrm{e}$ VD aumentados, com disfunção contrátil do VD. Análise ao Doppler revela regurgitação mitral leve e disfunção diastólica de VE de grau II (pseudonormal).

0 exame radiográfico contrastado de esôfago não evidenciou alterações funcionais ou morfológicas ${ }^{20}$.

$3^{\circ}$ caso: JSS, de 70 anos de idade, masculino, natural da Cidade de Barcelos, onde morou o primeiro ano de vida. 
Posteriormente foi morar numa comunidade na margem direita do Rio Negro até o ano 2002. Há dois anos, retornou a Cidade de Barcelos, onde reside atualmente. Nega ter recebido transfusão sanguínea. Refere ter sido fumante e etilista ocasional desde os 20 anos de idade até há 20 anos.

0 paciente trabalhou na extração da piaçaba dos 15 aos 56 anos de idade de forma continuada nos igarapés dos rios Curuduri, Aracá e Padauiri, resultando em 41 anos de exposição. Lá o paciente refere ter sido picado muitas vezes por triatomíneos, referindo, também, ter apresentado vários caroços após as picadas no tronco e extremidades. 0 paciente identificou o vetor em teste de reconhecimento.

Há quatro meses, saiu pela primeira vez do estado do Amazonas, quando foi encaminhado a Cidade de São Paulo para realizar uma avaliação cardíaca e receber orientação terapêutica. Lá realizou exames sorológicos para infecção chagásica com resultado positivo.

Refere quadro clínico de início subagudo há dois anos, com cansaço e dispnéia progressiva até apresentar ortopnéia e edema de membros inferiores. Atualmente, faz uso de captopril $75 \mathrm{mg}$ e furosemida $80 \mathrm{mg}$ diários e com o que permanece clinicamente compensado.

No exame físico estava afebril, com pulso regular a $84 \mathrm{bpm}$ e PA de 80/60mmHg. 0 ictus cordis era globoso e estava desviado para a esquerda e para abaixo um espaço intercostal. Na ausculta cardíaca destacava-se um ritmo em três tempos (presença de $3^{\mathrm{a}}$ bulha) e extra-sístoles isoladas, com sopro sistólico 3/6+ em foco mitral, irradiando para axila.

$\mathrm{Na}$ radiografia de tórax póstero-anterior verifica-se um moderado aumento da área cardíaca com índice cardiotorácico de 0,57 .

No registro eletrocardiográfico destaca-se um BRE de $3^{\circ}$ grau e EV isoladas.

0 ecocardiograma revela importante aumento dos diâmetros cavitários do VE, com aneurisma apical do tipo dedo de luva (Figura 4), afinamento e acinesia ínferoposterior e hipocinesia difusa dos demais segmentos do VE, com grave disfunção sistólica global $(\mathrm{FE}=29 \%)$. Observase ainda moderada disfunção contrátil do VD, com aumento dos seus diâmetros cavitários. Análise ao Doppler demonstra presença de insuficiência mitral moderada e disfunção diastólica de VE de grau I (déficit de relaxamento).

0 exame radiográfico contrastado de esôfago não evidenciou alterações funcionais ou morfológicas ${ }^{20}$.

Resultados dos exames diagnósticos. Os resultados dos exames sorológicos dos três pacientes com IFI, teste ELISA com antígeno convencional, teste ELISA recombinante (Cra-Fra) e a técnica de Western blot (TESA) para Trypanosoma cruzi foram positivos e estão especificados na Tabela 1. A hemocultura, o xenodiagnóstico e a reação em cadeia da polimerase (PCR) foram negativos para T. cruzi.

Os resultados dos exames radiográficos de tórax, eletrocardiográfico e ecocardiográfico estão sintetizados na Tabela 2.

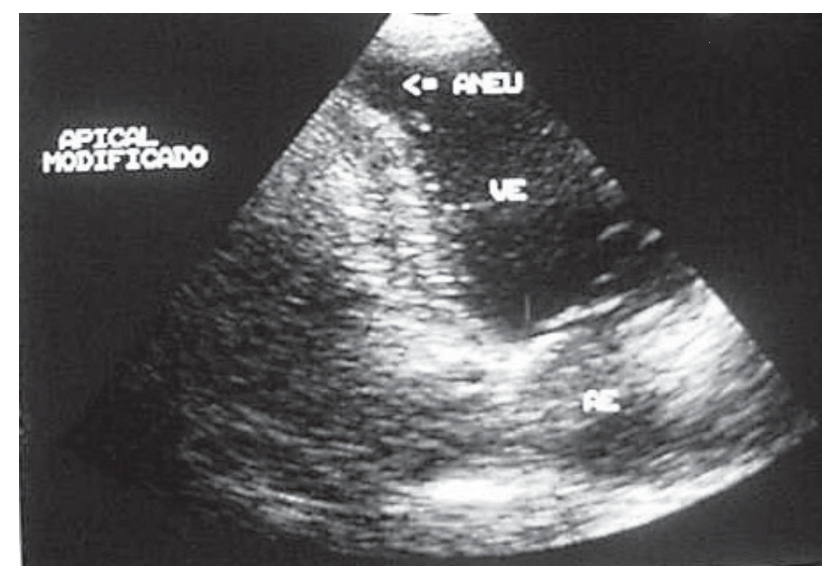

Figura 4 - Corte apical modificado revelando aneurisma de ponta em dedo de luva.

Tabela 1 - Resultados dos exames sorológicos de IFI, ELISA convencional, ELISA recombinante e TESA-blot para T. cruzi dos três pacientes estudados.

\begin{tabular}{lcccc}
\hline Casos & IFI & ELISA & ELISA (Cra-Fra) & TESA-blot \\
\hline Caso 1 & positivo & positivo & positivo & positivo \\
& $(1 / 160)$ & $(0,654)$ & $(1,421)$ & \\
Caso 2 & positivo & positivo & positivo & positivo \\
& $(1 / 80)$ & $(0,501)$ & $(0,842)$ & \\
Caso 3 & positivo & positivo & positivo & positivo \\
& $(1 / 320)$ & $(0,467)$ & $(1,099)$ & \\
\hline
\end{tabular}

$\overline{\text { Positivo para IFI a partir de título 1/40, para ELISA convencional ponto de corte } 0,357 \mathrm{e}}$ para ELISA (Cra-Fra) 0,241.

Tabela 2 - Síntese dos resultados dos exames radiográficos de tórax, eletro e ecocardiográficos.

\begin{tabular}{|c|c|c|c|c|c|c|}
\hline \multirow[b]{2}{*}{ Casos } & \multirow{2}{*}{$\begin{array}{c}\mathrm{Rx} \\
\text { Índice } \\
\text { cardiotorácico }\end{array}$} & \multirow[b]{2}{*}{ Eletrocardiograma } & \multicolumn{4}{|c|}{ Ecocardiograma } \\
\hline & & & $\begin{array}{c}\text { acinesia } \\
\text { ínfero-posterior }\end{array}$ & $\begin{array}{c}\text { aneurisma } \\
\text { de ponta }\end{array}$ & $\begin{array}{l}\text { diâmetros } \\
\text { do } V E(\mathrm{~cm})\end{array}$ & $\begin{array}{l}\text { fração de } \\
\text { ejeção (\%) }\end{array}$ \\
\hline Caso 1 & 0,62 & $\begin{array}{c}\text { BRD } 2^{\circ} \text { grau } \\
\text { HBAE, } \\
\text { EV polimórficas }\end{array}$ & $\operatorname{sim}$ & $\operatorname{sim}$ & $7,6 / 6,3$ & 35,0 \\
\hline Caso 2 & 0,56 & $\begin{array}{c}\text { BRD } 3^{\circ} \text { grau, } \\
\text { HBAE, } \\
\text { EV polimórficas }\end{array}$ & $\operatorname{sim}$ & $\operatorname{sim}$ & $6,7 / 6,2$ & 24,0 \\
\hline Caso 3 & 0,57 & $\begin{array}{l}\text { BRE } 3^{\circ} \text { grau, } \\
\mathrm{EV} \text { isoladas }\end{array}$ & $\operatorname{sim}$ & $\operatorname{sim}(*)$ & $8,9 / 7,6$ & 29,0 \\
\hline
\end{tabular}

(*) Aneurisma em dedo de luva. 


\section{DISCUSSÃo}

Neste trabalho, descrevemos três casos de insuficiência cardíaca em pacientes autóctones do Amazonas, com sorologia positiva para infecção pelo T. cruzi e características clínicas, eletrocardiográficas e ecocardiográficas sugestivas de cardiopatia chagásica crônica. Tradicionalmente, o diagnóstico de cardiopatia chagásica crônica se baseia na presença de sorologia positiva para infecção pelo T. cruzi acompanhada de evidências clínicas, eletrocardiográficas e radiológicas de acometimento cardíaco ${ }^{18}$. Apesar de não existir um padrão eletrocardiográfico específico de cardiopatia de etiologia chagásica, existem alterações que são consideradas sugestivas da doença devido à sua elevada frequiência e que ajudam a diferenciar de outras cardiopatias. Classicamente as alterações eletrocardiográficas mais freqüentes são o BRD, acompanhado ou não de HBAE, as EV polimórficas, bloqueios aurículo-ventriculares e zonas eletricamente inativas $^{1617}$.

A avaliação ecocardiográfica contribui para melhorar a precisão do diagnóstico, não somente por permitir identificar outras cardiopatias, mas também por revelar aspectos bastante típicos da cardiopatia chagásica ${ }^{1729}$. Ao contrário das outras cardiomiopatias dilatadas, que geralmente apresentam um padrão de disfunção contrátil do tipo difuso, o padrão de acometimento miocárdico mais freqüente na cardiopatia chagásica é segmentar. Aneurisma apical e acinesia ínferoposterior são as alterações segmentares mais frequientemente encontradas e, na ausência de cardiopatia isquêmica, sugerem fortemente o diagnóstico de cardiopatia chagásica crônica, principalmente quando encontradas de forma associada. Ressalte-se ainda que os aneurismas apicais geralmente apresentam aspectos morfológicos bastante típicos, descritos como mamilar, dedo de luva ou raquete de tênis ${ }^{3}$. Outro aspecto da cardiopatia chagásica crônica é o comprometimento freqüente e precoce do ventrículo direito, identificável ao ecocardiograma e que clinicamente se manifesta através do predomínio dos sinais de congestão venosa sistêmica, nos pacientes que desenvolvem insuficiência cardíaca.

Os três casos descritos apresentam elementos que permitem o diagnóstico de cardiopatia chagásica crônica. Todos os pacientes apresentavam padrão segmentar de acometimento miocárdico, com aneurisma apical e acinesia ínfero-posterior. Em dois deles o aspecto eletrocardiográfico também é o habitual da cardiopatia chagásica, com BRD, HBAE, EV polimórficas e APRV. 0 caso 3 apresentava alteração eletrocardiográfica menos freqüente na cardiopatia chagásica crônica (BRE e EV isoladas), que ocorre em 0,4 a 2,8\% dos $\operatorname{casos}^{18}$.

Neste último paciente, a presença de padrão segmentar de acometimento miocárdico, com típico aneurisma apical dedo de luva ao ecocardiograma torna o diagnóstico de cardiopatia de etiologia chagásica bem fundamentado. Deve-se chamar a atenção para a apresentação de dois casos fatais descritos anteriormente ${ }^{2}$, na mesma região, nos quais havia predominância de comprometimento do ventrículo esquerdo, inclusive com BRE em um deles. Por outro lado os estudos realizados até o presente na região do Rio Negro, indicam o aparecimento mais tardio da cardiopatia chagásica crônica ${ }^{1315}$.

Estes são os primeiros casos descritos de cardiopatia chagásica crônica autóctones da Amazônia brasileira com demonstração ecocardiográfica definida, mostrando a possibilidade de evolução para a forma crônica também na infecção pelo T. cruzi circulante na área. Outros estudos são necessários para definir o real perfil de morbidade cardíaca nesta forma de doença e a possível presença de outras formas clínicas, como a digestiva. A inusitada frequiência do comprometimento esquerdo, inclusive com BRE em dois dos cinco casos de cardiopatia chagásica crônica descritos na área até o presente (em um dos casos fatais anteriormente descritos ${ }^{2} \mathrm{e}$ em outro dos três descritos neste trabalho), também indica a necessidade de estudos com maior número de casos para esclarecer este perfil da doença.

\section{AGRADECIMENTOS}

Dra. Eufrosina Setsu Umezawa, pela confirmação sorológica através do TESA-blot. Júlio César Miguel, Laura Cristina Santos, Maria Celeste Dias Spata, Deise Lucide de Oliveira, pelos exames sorológicos, hemocultura, xenodiagnóstico e PCR. Ilenise Auxiliadora das Chagas Alexandre, pelo apoio operacional em Barcelos. Drs. João Renato Cortes e Jaime Portugal, da PROECho, pelo empréstimo do ecocardiógrafo portátil utilizado no estudo. Bio-Manguinhos - FIOCRUZ, pelos insumos para o imunodiagnóstico (IFI, ELISA convencional e ELISA recombinante).

\section{REFERÊNCIAS BIBLIOGRÁFICAS}

1. Acquatella H, Schiller NB, Puigbó JJ, Giordano H, Suárez JA, Casal H, Arreaza N, Valecillos R, Hirschhaut E. M-mode and two-dimensional echocardiography in chronic Chagas heart disease. A clinical and pathologic study. Circulation 62: 787-799, 1980.

2. Albajar PV, Laredo SV, Terrazas MB, Coura JR. Miocardiopatia dilatada em pacientes com infecção chagásica crônica. Relato de dois casos fatais autóctones do Rio Negro, Estado do Amazonas. Revista da Sociedade Brasileira de Medicina Tropical 36: 401-407, 2003.

3. Albanesi-Filho FM, Gomes-Filho JBM. A lesão apical do ventrículo esquerdo na evolução clínica da cardiopatia chagásica crônica. Arquivos Brasileiros de Cardiologia 56: 457-463, 1991.

4. Almeida E, Krieger MA, Carvalho MR, Oelemann W, Goldenberg S. Use of recombinant antigens for the diagnosis of Chagas disease and blood bank screening. Memórias do Instituto Oswaldo Cruz 85: 513-517, 1990.

5. Amico AF, Lichtenberg GS, Reisner SA, Stone CK, Schwartz RG, Meltzer RS. Superiority of visual versus computerized echocardiographic estimation of Valecillos R \& Hirschhaut E. M-mode and two-dimensional echocardiography in chronic Chagas heart disease. A clinical and pathologic study. Circulation 62: 787-799, 1980.

6. Amico AF, Lichtenberg GS, Reisner SA, Stone CK, Schwartz RG, Meltzer RS. Superiority of visual versus computerized echocardiographic estimation of radionuclide left ventricular ejection fraction. The American Heart Journal 118: 1259-1265, 1989.

7. Borges-Pereira J, Xavier SS, Pirmez C, Coura JR. Doença de Chagas em Virgem da Lapa, Minas Gerais, Brasil. IV. Aspectos clínicos e epidemiológicos do aneurisma ventricular esquerdo. Revista da Sociedade Brasileira de Medicina Tropical 31: 457-463, 1998. 
8. Britto C, Cardoso MA, Wincker P, Morel CM. A simple protocol for the physical cleavage of Trypanosoma cruzi kinetoplast DNA present in blood samples and its use in polymerase chain reaction (PCR)-based diagnosis of chronic Chagas' disease. Memórias do Instituto Oswaldo Cruz 88: 171-172, 1993.

9. Camargo ME. Fluorescent antibody test for the serodiagnosis of American trypanosomiasis. Technical modification employing preserved culture forms of Trypanosoma cruzi in a slide test. Revista do Instituto de Medicina Tropical de São Paulo 8: 227-234, 1966.

10. Camargo ME, Silva GR, Castilho EA, Silveira AC. Inquérito sorológico da prevalência da infecção chagásica no Brasil, 1975-1980. Revista do Instituto de Medicina Tropical de São Paulo 26: 192-204, 1984.

11. Cerisola JA, Rohwedder R, Segura EL, Del Prado CE, Alvarez M, Wynne GJ. El Xenodiagnóstico. Normalización. Utilidad. Imprenta Instituto Nacional de Investigaciones Cardiológicas, Buenos Aires, p. 127, 1974.

12. Chiari E, Dias JCP. Nota sobre uma Nova Técnica de Hemocultura para Diagnóstico Parasitológico na Doença de Chagas na Fase Crônica. Revista da Sociedade Brasileira de Medicina Tropical 9: 133-136, 1975

13. Coura JR, Junqueira ACV, Bóia MN, Fernandes 0, Bonfante C, Campos JE, Santos L, Devera R. Chagas disease in the Brazilian Amazon. IV. A new cross-sectional study. Revista do Instituto de Medicina Tropical de São Paulo 44: 159-165, 2002

14. Coura JR, Junqueira ACV, Fernandes O, Valente SAS, Miles MA. Emerging Chagas disease in Amazonian Brasil. Trends in Parasitology 18: 171-176, 2002

15. Coura JR, Willcox HPF, Arboleda MN, Fernandes 0, Paiva DD. Chagas disease in the Brazilian Amazon III. A cross-sectional study. Revista do Instituto de Medicina Tropical de São Paulo 37: 415-420, 1995.

16. Dias JCP, Kloetzel K. The prognostic value of the electrocardiographic features of chronic Chagas'disease. Revista do Instituto de Medicina Tropical de São Paulo 10: 158-162, 1968.

17. Maguire JH, Hoff R. Cardiac morbidity and mortality due to Chagas disease: prospective eletrocardiographic study of a brazilian community. Circulation 75: 1140-1145, 1987.
18. Marin-Neto JA, Simões MV, Sarabanda AVL. Forma crônica cardíaca. In: Brener Z, Andrade AA, Barral-Netto M (eds) Trypanosoma cruzi e doença de Chagas, 2a Edição. Guanabara-Koogan p. 266-296, 2000.

19. Pinto AYN, Harada GB, Valente VC, Abud JEA, Gomes FS, Souza GSR, Valente SAS. Acometimento cardíaco em pacientes com doença de Chagas aguda em microepidemia familiar, em Abaetuba, na Amazônia brasileira. Revista da Sociedade Brasileira de Medicina Tropical 34: 413-419, 2001.

20. Rezende JM, Moreira H. Chagasic megaesophagus and megacolon. Historical review and present concepts. Arquivos de Gastroenterologia 25 (special issue): 32-43, 1988.

21. Schenone H, Alfaro E, Reyes H, Taucher E. Valor del xenodiagnóstico en la infección chagásica crónica. Boletín Chileno de Parasitología 23: 149-154, 1968.

22. Shaw J, Lainson R, Fraiha H. Considerações sobre a epidemiologia dos primeiros casos autóctones de doença de Chagas registrados em Belém, Pará, Brasil. Revista de Saúde Pública 3: 153-157, 1969.

23. Silveira AC, Passos ADC. Altos índices de prevalência sorológica de infecção chagásica em área da Amazônia. Revista da Sociedade Brasileira de Medicina Tropical 19 (supl): 45, 1986.

24. Teicholz LE, Kreulen T. Problems in echocardiographic volume determinations: Echocardiographic correlations in the presence or absence of asynergy. The American Journal of Cardiology 37: 7-11, 1976.

25. Umezawa ES, Nascimento MS, Kesper NJ, Coura JR, Borges-Pereira J, Junqueira ACV, Camargo ME. Immunoblot Assay Using Excreted-Secreted Antigens of Trypanosoma cruzi in Serodiagnosis of Congenital, Acute, and Chronic Chagas' Disease. Journal of Clinical Microbiology 34: 2143-2147, 1996.

26. Valente SAS, Valente VC, Fraiha Neto H. Considerations on the epidemiology and transmission of Chagas disease in the Brazilian Amazon. Memórias do Instituto Oswaldo Cruz 94 (supl I): 395-398, 1999.

27. Valente SAS, Valente VC, Pinto AYN, Fraiha Neto H. Microepidemia familiar e transmissão oral da doença de Chagas na Amazônia brasileira. Memórias do Instituto Oswaldo Cruz 95 (supl II): 69-72, 2000.

28. Voller A, Draper C, Bidwell DE, Bartlett A. A microplate enzyme-linked immunosorbent assay (ELISA) for Chagas disease. Lancet 305: 426-428, 1975.

29. Xavier SS, Hasslocher-Moreno A, Pirmez C, Borges-Pereira J, Barroso PF. Echocardiographic Features of Chronic Chagas'Heart Disease. Anais do $46^{\text {th }}$ Congress of American College of Cardiology, p.145, 1997. 